\title{
Scale and Scope Economies in Banking: A Case Study of the Agricultural Development Bank of Pakistan
}

\author{
MuSLEH-Ud Din, EJAZ GHANI, and SARFRAZ K. QURESHI
}

\begin{abstract}
This paper examines the scale and scope efficiency of the Agricultural Development Bank of Pakistan. Using the production approach to measuring bank outputs and costs, a translog cost function is estimated to provide an assessment of the bank's scale and scope efficiency, and to quantify the extent to which its production costs are sensitive to size and output mix. Our results show that the bank enjoys both overall and product-specific economies of scale and, therefore, there exists scope for the bank to expand its operations at declining average cost. We show that even though bank branches in all size categories enjoy economies of scale, the extent of such economies is larger for branches operating at a smaller scale of production. This implies that as the bank branches grow larger in size in terms of both loan and deposit accounts, they move closer to attaining constant returns to scale. It is also shown that the marginal costs of servicing both loan and deposit accounts decline as bank branches grow larger in size in terms of either the number of loans or the number of deposits. This confirms that branches operating at a larger scale of production have attained greater cost efficiency in terms of servicing the loan and deposit accounts. As regards economies of scope, our results show that the bank's production technology is characterised by cost complementarity, which gives rise to cost savings through the joint production of loan and deposit accounts.
\end{abstract}

\section{INTRODUCTION}

The Agricultural Development Bank of Pakistan (ADBP) was established in 1961 by the merger of the Agricultural Finance Corporation and the Agricultural Bank of Pakistan with the primary objective of providing credit and other financial services to the agricultural sector. With a 64 percent share in total institutional lending to the agricultural sector in 1995, the ADBP has emerged as the country's largest single supplier of agricultural credit. The bank has a customer base of over 0.6 million clients, with loans outstanding of Rs 59,611 million. The bank made an

Musleh-ud Din and Ejaz Ghani are Research Economists and Sarfraz K. Qureshi is Director, Pakistan Institute of Development Economics, Islamabad.

Authors' Note: We would like to thank Professor Nasir M. Khilji for his helpful advice and comments. We would also like to express our gratitude to anonymous referees for their constructive comments, and to Mr Kalbe Abbas and Mr Akhtiar Shah for their excellent help in data processing and computational work. The usual disclaimer applies. 
all-time record disbursement of loans amounting to Rs 14,596 million, and mobilised deposits of Rs 1,385 million during the fiscal year 1995. However, despite the fact that the bank has made considerable progress in terms of its objective of providing easy access to agricultural credit, independent research studies have raised concerns about the bank's scale of operations and its long-term economic viability. ${ }^{1}$ In particular, these studies have pointed out that the bank's outreach is still limited-it serves only 17 percent of the farmers in a given community—and that the bank has low savings mobilisation rates ${ }^{2}$ and, consequently, remains highly dependent on the State Bank of Pakistan for its funding. In view of these considerations, these studies have recommended that the bank expand its lending operations in tandem with greater efforts to mobilise savings. It is in the light of these recommendations that the bank is currently pursuing a vigorous policy to enlarge its lending operations, broaden the range of its activities in the form of increased deposit mobilisation, and evolve into an economically viable financial institution. ${ }^{3}$

In order to expand its operations while remaining economically viable, the bank must exploit any cost advantages that are available to it by adopting the most cost-efficient size and product mix. The present paper examines the scale and scope efficiency of the Agricultural Development Bank of Pakistan in the light of various multiproduct cost attributes that are embedded in the bank's production technology. In particular, by estimating a translog cost function for the bank, we provide an assessment of its scale and scope efficiency, and quantify the extent to which its production costs are sensitive to its scale of operations. ${ }^{4}$ The paper is organised as follows. Section 2 presents the model. Section 3 discusses data and estimation issues. Section 4 presents the estimation results, while Section 5 contains some policy implications and concluding remarks.

\section{THE MODEL}

In the literature on bank cost studies, the bank is typically viewed as a multiproduct firm producing a variety of services, all of which can be regarded as different outputs. ${ }^{5}$ Recent advances in the theory of the multiproduct firm have emphasised that the empirical analysis of the scale and scope efficiency of such firms should focus on multiproduct cost attributes such as partial and overall economies of

${ }^{1}$ See, for example, International Development Ireland Ltd. (1993) and Qureshi (1995).

${ }^{2}$ The bank's total deposits as a percentage of total advances ranged from 2.65 to 9.31 during the 1991-1995 period.

${ }^{3}$ See, for instance, Agricultural Development Bank of Pakistan (1996).

${ }^{4}$ For an extensive survey of the literature on the scale and scope efficiency of rural financial institutions, see Desai and Mellor (1993).

${ }^{5}$ For a discussion of the bank as a multiproduct firm, see, for instance, Adar, Agmon, and Orgler (1975). 
scale, and cost complementarities that give rise to economies of scope. ${ }^{6}$ In this section, we specify a translog cost function that facilitates the treatment of multiproduct cost attributes by explicitly recognising the multiproduct nature of the banking firm. ${ }^{7}$ A translog cost function may be viewed as an exact cost function in its own right, or as a second-order logarithmic Taylor series approximation to any arbitrary twice-differentiable cost function. The translog cost function, in its most general form, can be written as:

$$
\begin{array}{r}
\ln c=\alpha_{0}+\sum_{i=1}^{m} \alpha_{i} \ln y_{i}+\sum_{j=1}^{n} \beta_{j} \ln p_{j}+\frac{1}{2} \sum_{i=1}^{m} \sum_{r=1}^{m} \delta_{i r} \ln y_{i} \ln y_{r}+ \\
\frac{1}{2} \sum_{j=1}^{n} \sum_{k=1}^{n} \gamma_{j k} \ln p_{j} \ln p_{k}+\sum_{i=1}^{m} \sum_{j=1}^{n} \theta_{i j} \ln y_{i} \ln p_{j} \quad \ldots \quad \ldots
\end{array}
$$

where $y_{i}$ are the $m$ outputs, and $p_{j}$ are the $n$ input prices. Linear homogeneity in factor prices is insured by the restrictions $\sum_{j} \beta_{j}=1, \sum_{j} \gamma_{j k}=0 \forall k$, and $\sum_{j} \theta_{i j}=0 \forall i$. Also, symmetry requires that $\delta_{i r}=\delta_{r i} \forall i, r$ and $\gamma_{j k}=\gamma_{k j} \forall j, k$. Equation (1) can be used to shed light on several technological attributes such as the overall and product-specific economies of scale, marginal costs, and cost complementarity. The rest of this section is devoted to a brief explanation of these concepts.

\section{Overall Economies of Scale}

Brown, Caves, and Christensen (1979), and Caves, Christensen, and Tretheway (1980) have defined an overall measure of scale economies as one minus the sum of cost elasticities with respect to each output. In terms of the translog cost function specified above, this measure of economies of scale can be calculated as follows:

$$
\text { OSE }=1-\sum_{i=1}^{m} \frac{\partial \ln c}{\partial \ln y_{i}}=1-\left(\sum_{i=1}^{m} \alpha_{i}+\sum_{i=1}^{m} \sum_{r=1}^{m} \delta_{i r} \ln y_{r}+\sum_{i=1}^{m} \sum_{j=1}^{n} \theta_{i j} \ln p_{j}\right) \ldots
$$

Overall economies of scale are said to exist if $O S E>0$. OSE $<0(=0)$ corresponds to diminishing (constant) returns to scale.

\section{Product-specific Economies of Scale}

The translog cost function also permits the evaluation of product-specific economies of scale. First of all, notice that $\partial \ln c / \partial \ln y_{i}$ is not a measure of product-

${ }^{6}$ See, for instance, Baumol, Panzar, and Willig (1982).

${ }^{7}$ The translog cost function is preferred over other specifications (e.g., Cobb-Douglas) for other reasons as well. For example, the translog cost function permits variable economies of scale and flexible elasticities of substitution and, therefore, the cost curves derived from the translog cost function are not restricted to the monotonically increasing or decreasing shapes imposed by the Cobb-Douglas or CES specifications. 
specific scale economies in the context of a multiproduct cost function. This is because the $i$ th output is only one output in a vector of outputs and $\partial \ln c / \partial \ln y_{i}<1$ can be consistent with product-specific diseconomies of scale. However, the derivative of the marginal cost curve provides an unambiguous measure of whether product-specific returns to scale are increasing or decreasing. The marginal cost of the ith product is given by:

$$
\frac{\partial c}{\partial y_{i}}=\left(\frac{\partial \ln c}{\partial \ln y_{i}}\right) \frac{c}{y_{i}} \quad \cdots \quad \ldots \quad \ldots
$$

Now the derivative of the above expression can be written as:

$$
\frac{\partial^{2} c}{\partial y_{i}^{2}}=\left(\left(\frac{\partial \ln \mathrm{c}}{\partial \ln y_{i}}\right)^{2}-\frac{\partial \ln \mathrm{c}}{\partial \ln y_{i}}+\frac{\partial^{2} \ln \mathrm{c}}{\partial \ln y_{i}^{2}}\right) \frac{c}{y_{i}^{2}} \quad \ldots \quad \ldots
$$

Product-specific economies (diseconomies) of scale exist if the above expression is negative (positive).

\section{Economies of Scope}

As mentioned above, an analysis of the cost efficiency of a multiproduct banking firm must also consider the possibility of cost savings from joint production. Willig (1979) has suggested that such cost savings can arise from inputs that are shared or utilised jointly without complete congestion. Baumol, Panzar, and Willig (1982) and Bailey and Friedlaender (1982) have also emphasised the cost or supplyside benefits from joint production. To ascertain whether or not the ADBP's production technology exhibits cost complementarity, we evaluate the sign of the following derivative:

$$
\frac{\partial^{2} c}{\partial y_{i} \partial y_{j}}=\left(\frac{\partial^{2} \ln c}{\partial \ln y_{i} \partial \ln y_{j}}+\left(\frac{\partial \ln c}{\partial \ln y_{i}}\right)\left(\frac{\partial \ln c}{\partial \ln y_{j}}\right)\right) \frac{c}{y_{i} y_{j}} \quad \ldots
$$

If the above expression is negative, then cost complementarity exists and the bank's production is characterised by some economies of scope. ${ }^{8}$

${ }^{8}$ This derivative indicates the presence or absence of economies of scope in the sense that it measures the extent to which marginal cost of the ith product changes due to a unit increase in the production of the jth output. Notice, however, that this measure sheds no light on the extent of economies of scope in terms of cost savings from joint versus specialised production. In this paper, we have not attempted to quantify the extent of economies of scope in the latter sense as it requires evaluation of the cost function at zero output levels, at which the translog function is undefined. For a detailed discussion of the difficulties which can arise in measuring economies of scope through the translog cost function, see Berger-Hanweck-Humphrey (1987) and Roller (1990). 


\section{DATA AND ESTIMATION ISSUES}

The data set employed in this study is largely from a survey of 341 branches of the ADBP for the years 1991-1995. ${ }^{9}$ There are two approaches to measuring bank outputs and cost: the production approach, and the intermediation approach. Under the production approach, banks are seen as producing accounts of various sizes by processing deposits and loans, incurring capital and labour costs. This approach measures output by the number of accounts and considers only operating cost. Under the intermediation approach, banks intermediate deposited and borrowed funds into loans and other assets. This approach measures output by the dollar value of accounts, considers both operating and interest costs, and treats deposits as inputs. We adopt the former approach in modelling a cost function for the banking operations of the ADBP. ${ }^{10}$ Accordingly, the bank is considered to produce two outputs, deposits, and loans, which are measured as the sum of all deposit and loan accounts, respectively, that are serviced by the bank. Such a measure of the output does not consider that the average size of deposit and loan accounts may rise as banks become larger, with a commensurate increase in the cost of servicing these accounts. To incorporate this, we include in the estimation an average account size variable, which is measured as the rupee value of loans (deposits) divided by the number of loan (deposit) accounts. In line with the production approach, our model includes two inputs: Labour and Capital. The wage rate is calculated as the sum of wages, salaries, and benefits divided by the total number of employees. The price of capital is computed as the sum of rent and depreciation divided by the book value of premises and equipment. ${ }^{11}$

\section{EMPIRICAL RESULTS}

The translog cost function is estimated using pooled time series and branchlevel cross-section data by Generalised Least Squares, ${ }^{12}$ with the homogeneity in

${ }^{9}$ This survey was conducted by the Pakistan Institute of Development Economics for a research project, sponsored by the State Bank of Pakistan and the World Bank, that aims to explore the nature of rural financial markets in Pakistan.

${ }^{10}$ Both these approaches have been extensively used in the literature on bank cost studies. In the present paper, the main reason for using the production approach is that the ADBP often receives funds at concessional rates of interest for on-lending purposes. Therefore, the use of operating cost inclusive of interest payments will give biased estimates of the scale and scope efficiency parameters.

${ }^{11}$ In computing the input prices for labour and capital, we have followed a number of earlier bank cost studies. See Gropper (1991), Hunter and Timme (1986), and Mitchell and Onvural (1996), among others.

${ }^{12}$ This estimation technique has been employed in view of the fact that the use of the cross-section and time series data set is likely to be associated with the problems of autocorrelation and heteroskedasticity. See Greene (1990) for technical details of the GLS estimation procedure as applied to the pooled data. 
input prices and symmetry restrictions imposed. The estimated parameters are reported in Table 1 . Most of the parameters are statistically significant, and the estimated model fits the data quite well as measured by the values of $\bar{R}^{2}$ and $F$ statistic. We tested to determine if the general translog cost function is a statistically significant improvement over the Cobb-Douglas functional form. The Cobb-Douglas

Table 1

Estimated Translog Cost Function

\begin{tabular}{|c|c|c|c|}
\hline Variables & Coefficients & Variables & Coefficients \\
\hline Constant & $\begin{array}{c}2.561 \\
(3.925)^{* *}\end{array}$ & Loans $\times$ Deposits & $\begin{array}{l}-0.058 \\
(-2.799) * *\end{array}$ \\
\hline Loans & $\begin{array}{l}0.457 \\
(3.646)^{* *}\end{array}$ & $\begin{array}{l}\text { Loans } \times \text { Avg. Loan } \\
\text { Size }\end{array}$ & $\begin{array}{c}0.014 \\
(0.407)\end{array}$ \\
\hline Deposits & $\begin{array}{l}-0.293 \\
(-1.889)^{*}\end{array}$ & $\begin{array}{l}\text { Deposits } \times \text { Avg. Dep. } \\
\text { Size }\end{array}$ & $\begin{array}{l}0.049 \\
(2.665)^{* *}\end{array}$ \\
\hline Avg. Loan Size & $\begin{array}{l}0.213 \\
(2.384)^{* *}\end{array}$ & $\begin{array}{l}\text { Loans } \times \text { Price of } \\
\text { Capital }\end{array}$ & $\begin{array}{l}0.085 \\
(4.137)^{* *}\end{array}$ \\
\hline Avg. Deposit Size & $\begin{array}{c}-0.099 \\
(-0.819)\end{array}$ & Loans $\times$ Wage Rate & $\begin{array}{l}-0.085 \\
(-4.138)^{* *}\end{array}$ \\
\hline Price of Capital & $\begin{array}{l}0.284 \\
(2.366)^{* *}\end{array}$ & $\begin{array}{l}\text { Deposits } \times \text { Price of } \\
\text { Capital }\end{array}$ & $\begin{array}{c}-0.021 \\
(-1.149)\end{array}$ \\
\hline Wage Rate & $\begin{array}{c}0.716 \\
(5.886)^{* *}\end{array}$ & Deposits $\times$ Wage Rate & $\begin{array}{c}0.021 \\
(1.149)\end{array}$ \\
\hline Loans Squared & $\begin{array}{l}0.081 \\
(2.320)^{* *}\end{array}$ & $\begin{array}{l}\text { Avg. Loan Size } \times \text { Price } \\
\text { of Capital }\end{array}$ & $\begin{array}{l}0.070 \\
(2.507)^{* *}\end{array}$ \\
\hline Deposits Squared & $\begin{array}{l}0.155 \\
(5.090) * *\end{array}$ & $\begin{array}{l}\text { Avg. Loan Size } \times \text { Wage } \\
\text { Rate }\end{array}$ & $\begin{array}{l}-0.070 \\
(-2.507)^{* *}\end{array}$ \\
\hline Avg. Loan Size Squared & $\begin{array}{c}-0.061 \\
(-1.330)\end{array}$ & $\begin{array}{l}\text { Avg. Dep. Size } \times \text { Price } \\
\text { of Capital }\end{array}$ & $\begin{array}{c}-0.010 \\
(-0.771)\end{array}$ \\
\hline Avg. Deposit Size Squared & $\begin{array}{l}0.039 \\
(1.890)^{*}\end{array}$ & $\begin{array}{l}\text { Avg. Dep. Size } \times \text { Wage } \\
\text { Rate }\end{array}$ & $\begin{array}{c}0.010 \\
(0.771)\end{array}$ \\
\hline Price of Capital Squared & $\begin{array}{l}0.094 \\
(6.660) * *\end{array}$ & $\begin{array}{l}\text { Wage Rate } \times \text { Price of } \\
\text { Capital }\end{array}$ & $\begin{array}{l}-0.094 \\
(-6.660)^{* *}\end{array}$ \\
\hline Wage Rate Squared & $\begin{array}{l}0.094 \\
(6.660) * *\end{array}$ & $\begin{aligned} \bar{R}^{2} & =0.645 \\
F & =116.887\end{aligned}$ & \\
\hline
\end{tabular}

t-statistics in parantheses.

* Indicates significance at 10 percent.

** Indicates significance at 5 percent. 
requires that all second-order parameters equal zero in Equation (1). The likelihood ratio test statistic of 119.37 far exceeds the critical value of $\chi^{2}$ at 5 percent level of significance with 12 degrees of freedom (21.03). Hence the hypothesis of CobbDouglas functional form is decisively rejected. Next, we tested for homotheticity in the form of separability of the cost function in the outputs and all other variables. The separability restriction requires that the relative marginal costs of producing the outputs be independent of the levels of input prices and implies that $\theta_{i j}=0$ in Equation (1). In this case also, the likelihood ratio test statistic of 41.31 exceeds the critical value of $\chi^{2}$ at 5 percent level of significance with 4 degrees of freedom (9.49). Therefore, the restriction of separability of the cost function is also rejected. ${ }^{13}$

Table 2 presents yearly estimates of the key technological parameters of the bank's production process. The elasticities of cost with respect to loan and deposit accounts are close to each other, showing slight variation during the sample period. As indicated by the overall scale economy parameter, the bank has enjoyed substantial overall economies of scale throughout the sample period. The marginal cost of servicing a loan account was Rs 1779 in 1991. It rose to the highest level, of Rs 2538, in 1994, declining sharply to Rs 1390 in 1995. The marginal cost of servicing a deposit account was considerably lower than that of servicing a loan account during the entire sample period. ${ }^{14}$ It ranged from Rs 409 to Rs 628 during the sample period, the highest figure corresponding to the year 1994. The negative signs of the derivatives of marginal costs of servicing loan and deposit accounts confirm that the bank has enjoyed product-specific economies of scale with respect to the production of both loan and deposit accounts. Similarly, the negative sign of the expression of cost complementarity reflects the fact that the bank's production technology has been characterised by economies of scope.

In Table 3, we have computed the values of cost elasticities and marginal costs by grouping the bank branches according to the number of loan accounts. The elasticity of cost with respect to loan accounts is 0.215 in the first group (less than 1000 loan accounts), increasing to 0.494 in the group corresponding to 4000 or greater loan accounts. The marginal cost of servicing a loan account is Rs 2345 in the first group, the highest in all size categories. However, this marginal cost is much lower-Rs 258-for an average branch in the size category of 4000 or more loan accounts. The elasticity of cost with respect to deposit accounts declines from 0.225

${ }^{13}$ In both these tests, linearity of the cost function in input prices is the maintained hypothesis.

${ }^{14}$ The principal reason for the relatively high marginal cost of servicing a loan account is the fact that the average size of a loan account is much larger than the average size of a deposit account. Furthermore, processing a loan account involves a broader range of activities such as collection of information on the credit-worthiness of the borrower, maintaining regular contacts with the borrower to ensure timely payment of loan instalments, and legal procedures to design and implement loan contracts. These additional services pertaining to the maintenance of loan accounts may also explain why the marginal cost of servicing a loan account is higher than that of servicing a deposit account. 
Table 2

Year-wise Point Estimates of Cost Elasticities and Marginal Costs

\begin{tabular}{lcccccc}
\hline Parameters & 1991 & 1992 & 1993 & 1994 & 1995 & Average \\
\hline Cost Elasticity wrt Loans & 0.230748 & 0.235433 & 0.245735 & 0.205994 & 0.219653 & 0.227310 \\
Cost Elasticity wrt Deposits & 0.235560 & 0.231605 & 0.191062 & 0.220408 & 0.202404 & 0.216029 \\
Overall Economies of Scale & 0.533691 & 0.532963 & 0.563203 & 0.573598 & 0.577942 & 0.566661 \\
Marginal Cost of Loans & 1779.000 & 2373.000 & 1698.000 & 2538.000 & 1390.000 & 1858.000 \\
Marginal Cost of Deposits & 409.0000 & 466.0000 & 463.0000 & 628.0000 & 487.0000 & 493.000 \\
Derivative of MC Loans & -2.34000 & -3.45000 & -1.41000 & -2.95000 & -1.01000 & -1.89613 \\
Derivative of MC Deposits & -0.60200 & -0.79100 & -0.82800 & -0.59300 & -0.06970 & -0.283248 \\
Cost Complementarity & -0.02210 & -0.02690 & -0.05410 & -0.10700 & -0.05900 & -0.051806 \\
\hline
\end{tabular}

${ }^{a}$ Refers to the magnitude of the derivative in Equation (5).

Table 3

Point Estimates of Cost Elasticities and Marginal Costs, by Size of Bank Branches ${ }^{\mathrm{a}}$

\begin{tabular}{lccccc}
\hline Parameters & $<1000$ & $\begin{array}{l}1000- \\
<2000\end{array}$ & $\begin{array}{c}2000- \\
<3000\end{array}$ & $\begin{array}{c}3000- \\
<4000\end{array}$ & $>4000$ \\
\hline Cost Elasticity wrt Loans & 0.215236 & 0.369989 & 0.411603 & 0.439335 & 0.493569 \\
Marginal Cost of Loans & 2345.000 & 889.0000 & 600.0000 & 456.0000 & 258.0000 \\
Cost Elasticity wrt Deposits & 0.224812 & 0.112808 & 0.082690 & 0.062619 & 0.023366 \\
Marginal Cost of Deposits & 514.0000 & 258.0000 & 189.0000 & 143.0000 & 53.00000 \\
Overall Economies of Scale & 0.559952 & 0.517202 & 0.505707 & 0.498046 & 0.483065 \\
\hline
\end{tabular}

${ }^{\text {a }}$ Branch size measured by the number of loan accounts.

Table 4

Point Estimates of Cost Elasticities and Marginal Costs, by Size of Bank Branches ${ }^{\mathrm{a}}$

\begin{tabular}{lccccc}
\hline Parameters & $<2000$ & $\begin{array}{l}2000- \\
<4000\end{array}$ & $\begin{array}{l}4000- \\
<6000\end{array}$ & $\begin{array}{l}6000- \\
<8000\end{array}$ & $>8000$ \\
\hline Cost Elasticity wrt Loans & 0.249182 & 0.171528 & 0.135479 & 0.119760 & 0.101563 \\
Marginal Cost of Loans & 2036.000 & 1402.000 & 1107.000 & 979.0000 & 830.0000 \\
Cost Elasticity wrt Deposits & 0.158075 & 0.364407 & 0.460191 & 0.501958 & 0.550307 \\
Marginal Cost of Deposits & 609.0000 & 449.0000 & 309.0000 & 259.0000 & 208.0000 \\
Overall Economies of Scale & 0.592743 & 0.464065 & 0.404330 & 0.378282 & 0.34813 \\
\hline
\end{tabular}

${ }^{a}$ Branch size measured by the number of deposit accounts. 
in the first group to 0.023 in the final group. The marginal cost of servicing a deposit account also varies inversely with the branch size, declining sharply from Rs 514 in the first group to Rs 53 in the group corresponding to 4000 or more loan accounts. The value of the overall economies-of-scale parameter is 0.559 , corresponding to the first group. This value gradually declines to 0.483 in the final group.

Table 4 reports the values of cost elasticities and marginal costs by grouping the bank branches according to the number of deposit accounts. In this case, the elasticity of cost with respect to loan accounts declines from 0.249 in the first group (less than 2000 deposit accounts) to 0.101 in the last group (8000 or more deposit accounts). The marginal cost of servicing a loan account is Rs 2036 in the first group, declining sharply to Rs 830 in the final group. The elasticity of cost with respect to deposit accounts varies directly with the branch size, increasing from 0.158 in the first group to 0.550 in the final group. The marginal cost of servicing a deposit account is Rs 609 in the first group and declines gradually to Rs 208 in the final group. The overall economies-of-scale parameter declines from 0.592 in the first group to 0.348 in the last group.

In summary, then, the above results show that the elasticity of cost with respect to loan accounts increases as the bank branches grow larger in size in terms of the number of loan accounts. On the other hand, the marginal cost of servicing a loan account, the elasticity of cost with respect to deposit accounts, the marginal cost of servicing a deposit account, and the overall economies-of-scale parameter decline as the number of loan accounts increases. In the case where the bank branches are grouped according to the number of deposit accounts, the elasticity of cost with respect to loan accounts, the overall economies-of-scale parameter, and the marginal costs of servicing both the loan and deposit accounts decline as the branch size increases in terms of the number of deposit accounts. However, the elasticity of cost with respect to deposit accounts increases as the bank branches grow larger in size in terms of the number of deposit accounts.

\section{CONCLUDING REMARKS}

This paper has analysed the scale and scope efficiency of the branch-level banking operations of the Agricultural Development Bank of Pakistan in terms of a multiproduct translog cost function. The primary findings of this study can be summarised as follows. First, the bank's production technology exhibits both overall and product-specific economies of scale. Second, even though bank branches in all size categories enjoy economies of scale, the extent of such economies is larger for branches operating at a smaller scale of production. This implies that as the bank branches grow larger in size in terms of both loan and deposit accounts, they move closer to attaining constant returns to scale. Third, the marginal costs of servicing both loan and deposit accounts decline as bank branches grow larger in size in terms 
of either the number of loans or the number of deposits. This confirms that the branches operating at a larger scale of production have attained greater cost efficiency in terms of servicing loan and deposit accounts. Finally, our results show that the bank's production technology is characterised by cost complementarity. Hence, there exists scope for cost savings through the joint production of loan and deposit accounts.

Future expansion of the banking operations of the Agricultural Development Bank of Pakistan needs to be carefully evaluated in the light of cost efficiency considerations. The empirical evidence on the bank's branch-level cost attributes has important policy implications in this regard. For example, in view of the finding that the bank's branches are underutilised, in the sense that they are capable of handling more loan and deposit accounts with a less than proportionate increase in operating costs, the bank's efforts to evolve into an economically viable financial institution should focus on achieving greater cost efficiency through an optimal utilisation of its branches. Furthermore, the bank's policy to expand its operations should focus not only on enlarging its lending operations but also on expanding deposit mobilisation. In this way, the bank can exploit economies of scale as well as economies of scope. In addition, greater emphasis on deposit mobilisation will also allow the bank to reduce its dependence on concessional borrowings and transform itself into a selfsustaining financial institution.

We may conclude by spelling out some of the limitations of our analysis. First, some caution in interpreting our results is warranted in view of the fact that the timeperiod covered in this study - 5 years - is rather short for studying the question of economies of scale, which is essentially a long-run concept. Second, in view of the fact that we have not included in our analysis the administrative expenses incurred by the head office and various regional offices of the bank, our study implies the presence of scale and scope economies only in terms of branch-level operating costs. While the issue of the scale and scope efficiency of the ADBP at the programme level can be dealt with in a framework that utilises aggregate data on the relevant variables, ${ }^{15}$ it is not pursued here given our primary interest in studying the branchlevel cost attributes of the ADBP.

\section{REFERENCES}

Adar, Z., T. Agmon and Y. Orgler (1975) Output Mix and Jointness in Production in the Banking Firm. Journal of Money, Credit, and Banking 7: 235-244.

Agricultural Development Bank of Pakistan (1996) ADBP Outlook. Islamabad: ADBP.

\footnotetext{
${ }^{15}$ To be precise, such an approach would also include the number of bank branches as an explanatory variable in the cost function.
} 
Bailey, E., and A. Friedlaender (1982) Market Structure and Multiproduct Industries. Journal of Economic Literature 20: 1024-1048.

Baumol, W., J. Panzar and R. Willig (1982) Contestable Markets and the Theory of Industry Structure. San Diego, Calif.: Harcourt Brace Jovanovich.

Berger, A., G. Hanweck and D. Humphrey (1987) Competitive Viability in Banking: Scale, Scope, and Product Mix Economies. Journal of Monetary Economics 20: 501-520.

Brown, R., W. Caves and L. Christensen (1979) Modelling the Structure of Cost and Production in Multiproduct Firms. Southern Economic Journal 48: 970-984.

Caves, W., L. Christensen and M. Tretheway (1980) Flexible Cost Function for Multi-product Firms. Review of Economics and Statistics 62: 477-481.

Desai, B. M., and J. W. Mellor (1993) Institutional Finance for Agricultural Development: An Analytical Survey of Critical Issues. Washington, D. C.: International Food Policy Research Institute.

Greene, W. (1990) Econometric Analysis. New York: Macmillan.

Gropper, D. (1991) An Empirical Investigation of Changes in Scale Economies for the Commercial Banking Firm, 1979-1986. Journal of Money, Credit, and Banking 23: 718-727.

Hunter, W., and S. Timme (1986) Technical Change, Organisational Form, and Structure of Bank Production. Journal of Money, Credit, and Banking 18: $152-$ 166.

International Development Ireland (1993) Review of Agricultural Development Bank of Pakistan. (Unpublished).

Mitchell, K., and N. Onvural (1996) Economies of Scale and Scope at Large Commercial Banks: Evidence from the Fourier Flexible Functional Form. Journal of Money, Credit, and Banking 28: 178-199.

Qureshi, S. K. (1995) Report of the Sub-Committee on Economic Viability of the ADBP and FBC and the Causes of Collapse of the Cooperative Movement. (Unpublished).

Roller, L. (1990) Proper Quadratic Cost Functions with an Application to the Bell System. Review of Economics and Statistics 72: 202-210.

Willig, R. (1979) Multiproduct Technology and Market Structure. American Economic Review 69: 346-351. 